\title{
The Rauischholzhausen Agenda for Road Ecology
}

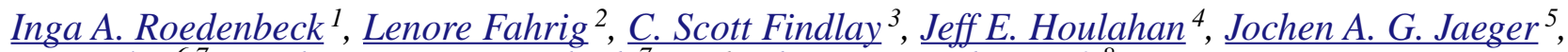
Nina Klar $^{6,7}$, Stephanie Kramer-Schadt ${ }^{7}$, and Edgar A. van der Grift ${ }^{8}$

\begin{abstract}
Despite the documented negative effects of roads on wildlife, ecological research on road effects has had comparatively little influence on road planning decisions. We argue that road research would have a larger impact if researchers carefully considered the relevance of the research questions addressed and the inferential strength of the studies undertaken. At a workshop at the German castle of Rauischholzhausen we identified five particularly relevant questions, which we suggest provide the framework for a research agenda for road ecology: (1) Under what circumstances do roads affect population persistence? (2) What is the relative importance of road effects vs. other effects on population persistence? (3) Under what circumstances can road effects be mitigated? (4) What is the relative importance of the different mechanisms by which roads affect population persistence? (5) Under what circumstances do road networks affect population persistence at the landscape scale? We recommend experimental designs that maximize inferential strength, given existing constraints, and we provide hypothetical examples of such experiments for each of the five research questions. In general, manipulative experiments have higher inferential strength than do nonmanipulative experiments, and full before-after-control-impact designs are preferable to before-after or control-impact designs. Finally, we argue that both scientists and planners must be aware of the limits to inferential strength that exist for a given research question in a given situation. In particular, when the maximum inferential strength of any feasible design is low, decision makers must not demand stronger evidence before incorporating research results into the planning process, even though the level of uncertainty may be high.
\end{abstract}

Key Words: road ecology; research agenda; experimental design; hierarchy of study designs; methodological standard; before-after-control-impact design; before-after design; control-impact design; inferential strength; weight of evidence; uncertainty; landscape scale; extrapolation; population persistence; road networks; road effects; mitigation; decision making

\section{INTRODUCTION}

Mobility of people and goods is an essential component of the modern world, with its emphasis on globalization and economic opportunity. However, the transportation infrastructure that enhances connectivity among human settlements often results in decreased connectivity among remaining natural habitats and wildlife populations. It is estimated that the transportation infrastructure affects at least $19 \%$ of the conterminous land area of the United States (Forman 2000) and 20\% of the Netherlands (Reijnen et al. 1995). Areas larger than $100 \mathrm{~km}^{2}$ that were unfragmented by roads decreased from $22 \%$ to $14 \%$ of the total land coverage of the old West German states between 1977 and 1998 (Bundesamt für Naturschutz 1999), and this trend is very likely to continue in most parts of the world (e.g., NRTF 1997).

Although there is now a growing body of evidence of the negative impacts of roads on wildlife (Trombulak and Frissell 2000, Underhill and Angold 2000, Forman et al. 2002, Sherwood et al. 2002, Spellerberg 2002), ecological research has had comparatively little effect on decision making in transportation planning (OECD 2002, UBA 2003). In part, this reflects the fact that, in the face of compelling economic and social arguments for road siting, design, and construction, the effects on 
ecological values are usually considered of secondary importance (Caid et al. 2002, Bratzel 2005). However, this lack of resonance also relates to the nature of road research itself. Maximizing the impact of road research in the decision-making process requires that (1) the questions addressed by road ecologists be directly relevant to the practical issues of road planning and construction and (2) road studies be designed so as to have high evidentiary weight. Much of the road research undertaken thus far fails to satisfy at least one, and often both, of these conditions (see the subsection on the current state of road ecology research), with the result that ecological arguments often must appeal to general decision-making principles such as the precautionary principle (Myers 1993, Underwood 1997). These are frequently viewed as unscientific apologetics, especially in the face of compelling economic counterarguments (Foster et al. 2000, Sunstein 2003, Goldstein and Carruth 2004).

In this paper we suggest ways to make road research more relevant and effective by addressing questions of direct management concern and designing studies that have high inferential strength. We begin by identifying the questions in road ecology of most direct relevance to the decision-making process. We then describe how the inferential strength of studies is influenced by study design and extrapolation. We proceed to a methodological standard for road ecology research by specifying, for each of the research questions identified, a hierarchy of experimental designs. We conclude with a discussion of the implications for road ecology researchers, planners, and funding organizations.

\section{RELEVANT QUESTIONS IN ROAD ECOLOGY}

The design and operation of road networks that minimize ecological impacts requires an understanding of how roads affect wildlife populations and how negative effects can be mitigated. These practical needs give rise to five empirical research questions.

\section{Question 1: Under what circumstances do roads affect population persistence?}

Despite a fair amount of literature on the effects of roads on animals (reviewed in Glitzner et al. 1999, Jackson 2000, Trombulak and Frissell 2000,
Underhill and Angold 2000, Forman 2002 [ERRA TUM]), very few studies evaluate the effects of roads at the population level. Most studies either document road mortality or evaluate the effects of roads and traffic on animal movement, neither of which allows strong inference about the impacts on population viability; for example, it is possible that increased reproduction rates counterbalance losses caused by traffic mortality (see the subsection on the current state of road ecology research). Because the extent to which a road affects population persistence may depend on the particular circumstances, it seems likely that answering this question will depend on synthesizing the results from a set of studies conducted under a variety of circumstances.

\section{Question 2: What is the relative importance of road effects vs. other impacts on population persistence?}

Roads are only one of a suite of anthropogenic stressors to which wildlife populations are exposed. Developing efficient and effective strategies for mitigating population declines requires knowledge of the relative importance of different stressors and the extent to which they interact. This represents an enormous logistical challenge, especially because estimating interactions requires factorial-design experiments.

\section{Question 3: Under what circumstances can road effects be mitigated?}

Assuming that roads have negative effects on wildlife populations and that roads contribute substantially to the decline of wildlife populations relative to other impacts, the obvious planning question is the extent to which road effects can be mitigated, and at what economic cost. Mitigation may include modification of road siting, design, and construction as well as the installation of barriers, speed limits, noise screens, and under- or over-road wildlife passageways (Iuell et al. 2003).

Mitigation may not guarantee a viable population, because the starting point of no roads may have already been a nonviable population. Moreover, mitigation may only be partial, but, if it substantially improves population viability, it may be considered successful. The extent to which a particular road effect can be mitigated depends on the particular 
circumstances, such as the biology of the target species, road characteristics, or neighboring habitat, and the choice and design of the particular mitigation measure (Clevenger 2002). Therefore, as with the first question, it seems likely that answering this question will depend on synthesizing the results from a set of studies conducted under a variety of circumstances.

\section{Question 4: What is the relative importance of the different mechanisms by which roads affect population persistence?}

There are four major categories of primary road effects (Van der Zande et al. 1980, Forman 1995, Iuell et al. 2003): (1) mortality from collisions with vehicles; (2) hindrance to movement causing reduced access to resources and mates; (3) disturbance caused by noise, dust, light, and heavy metal pollution, leading to the degradation of habitat quality; and (4) habitat loss caused by disturbance effects in the wider environment and from the physical occupation of land by the road. In addition, road construction is often followed by various indirect effects such as increased human access causing disturbance of breeding sites, increased exploitation via activities such as hunting (McLellan and Shackleton 1988, Kilgo et al. 1998), and the spread of invasive species (Parendes and Jones 2000).

Knowledge of the relative importance of the different road impacts makes it possible to focus mitigation efforts on alleviating the most harmful effects (Osenberg and Schmitt 1996). For example, fencing may effectively mitigate road mortality, but if the major impact is reduced habitat connectivity, fencing may do more harm than good (Jaeger and Fahrig 2004).

Well-designed studies that identify effective mitigation measures can also demonstrate which negative effects of roads are the largest. On the other hand, there are mitigation strategies that are capable of mitigating multiple effects. For example, if a wildlife overpass is shown to be effective, it remains unclear whether this is because of decreased road mortality, increased movement, or both.
Question 5: Under what circumstances do road networks affect population persistence at the landscape scale?

Newly constructed roads add to the existing road network and may affect wildlife at both local and landscape scales (Forman 1995). The scale of an investigation is, among other things, dependent on the area requirements of the species observed, and landscape-scale effects may be particularly relevant for species with large home ranges. Some landscape-scale road effects can be studied at a local scale and extrapolated to the landscape, albeit with attendant extrapolation issues. Other landscapescale effects must be directly addressed at a landscape scale, for example, questions about how the configuration of road networks affects population persistence. Landscape-scale studies may provide, for example, information about where in the landscape mitigation wildlife overpasses or fences should be placed.

\section{SOUND ROAD ECOLOGY}

\section{About inferential strength}

For any scientific question under study, there is the truth that the experimenter is attempting to uncover and the actual result derived from the experiment. Hence, the key question in any scientific study is: Given a set of results, what is the strength, i.e., validity, of the inference that the hypothesis tested is true or false? The probability for the inference that the result is indeed the truth is associated with a specific level of uncertainty. Low strength of inference means high uncertainty. To counterbalance economic arguments, road ecology studies need to be designed with the highest inferential strength possible, and doing sound road ecology requires study designs with high inferential strength wherever such studies are feasible.

The inferential strength of a study depends on (1) the number of competing hypotheses tested, (2) the study design, and (3) the extent to which one must extrapolate from the context in which the study was conducted to the context of concern, i.e., the particular decision context. Inferential strength increases with the number of competing hypotheses tested because there are always many possible hypotheses consistent with any given experimental result (Chamberlin 1965). With respect to study design, experimental manipulations generally have 
higher inferential strength than do correlation studies, because of the generally greater ability to control confounding factors. Inferential strength declines with increasing extrapolation, because the greater the extrapolation, the less likely it is that the causal structure of the experimental domain is mimicked in the domain of real interest.

\section{Hierarchy of study designs}

We distinguish between two major dimensions of study design: (1) study class and (2) study type. With regard to study class, we distinguish between manipulative and nonmanipulative studies. The main difference is that the manipulative study is prospective, looking forward in time, whereas the nonmanipulative study is retrospective, looking backwards in time (Sahai and Sahai 1996). For example, a manipulative study might monitor a population in a location in which a road is planned and then continue to monitor that population during and after road construction. In a nonmanipulative study, data from a site before and after a road was built may be available, and the researcher assesses retrospectively what happened to the population. The main problem with a nonmanipulative study is that some of the information needed, e.g., historical habitat data, may be unavailable or nonexistent. Manipulative studies have higher inferential strength, because the researchers conduct the study knowing that the manipulation, e.g., road construction, will occur. This allows collection of all the relevant data before, during, and after the manipulation. Furthermore, if the researchers are integrated into the road planning project, they may have some control over the design of the manipulation itself.

The study type with the highest inferential strength for assessing human impacts on the environment is the before-after-control-impact (BACI) design (Green 1979, Underwood and Chapman 2003). In this design, the sites affected by the human impact (I) are compared with unaffected control sites (C) both before (B) and after (A) some intervention. If the difference in the environmental variable of interest, e.g., wildlife population size, between the control and impact sites is greater after the impact than before, this is strong evidence that the intervention has caused the observed change. BACIs should have replication in space, i.e., several control and impact sites should be studied (Underwood 1992), and replication in time, i.e., the environmental variable(s) should be measured multiple times both before and after the impact (Bernstein and Zalinski 1983, Stewart-Oaten et al. 1986).

In some situations, a complete BACI study is not possible, and there are two partial designs of lower inferential strength. In before-after (BA) designs, a site or sites is studied before (B) and after (A) an impact, but there are no control sites. If the environmental variable, e.g., population size, changes after the impact, that is probably because of the impact. However, because there are no control sites, the possibility that the observed change was caused by something other than the observed impact cannot be excluded (Osenberg and Schmitt 1996).

In the control-impact $(\mathrm{CI})$ design, data exist only for the period after the impact. Affected sites, e.g., sites with roads, are compared with unaffected sites. If control (C) and impact (I) sites differ with regard to the environmental variable, the inference is that this difference is because of the intervention. Clearly, this inference is valid only if control and impact sites are identical in the absence of the intervention, an assumption that cannot be tested, because the BA component is missing (Osenberg and Schmitt 1996). Replication in space of both C and I sites can reduce this problem, but not eliminate it. A correlation study measuring the environmental variable in sites along a gradient of the impact, e.g., road density, represents a common type of CI design.

Although a replicated, manipulative BACI design is desirable, it cannot be used in situations in which there are no control sites, randomization of sites to treatments is not possible, no data from the period before impacts are available, and/or financial resources are limited. As such, we can develop a rough hierarchy of experimental designs ranked according to their a priori inferential strength. Unfortunately, feasibility declines with inferential strength, because the greater the inferential strength of a study, the greater the number of design requirements that must be fulfilled and the number of resources required to fulfill them. Hence, for each design one can also estimate a degree of feasibility depending on costs and the availability of the required data, and a recommendation of expedience based on feasibility and inferential strength (Fig. 1). 
Fig. 1. The Rauischholzhausen agenda for road ecology: five key questions and potential study designs. There are two study classes, manipulative $(\mathrm{m})$ and nonmanipulative $(\mathrm{nm})$, and three study types: beforeafter-control-impact (BACI), before-after (BA), and control-impact (CI). Column height indicates inferential strength in ordinal ranks: (1) low, (2) medium, (3) high, and (4) very high. For each design, we provide a qualitative estimate of feasibility in terms of cost, likelihood of required data being available, etc., and a recommendation based on feasibility and inferential strength.

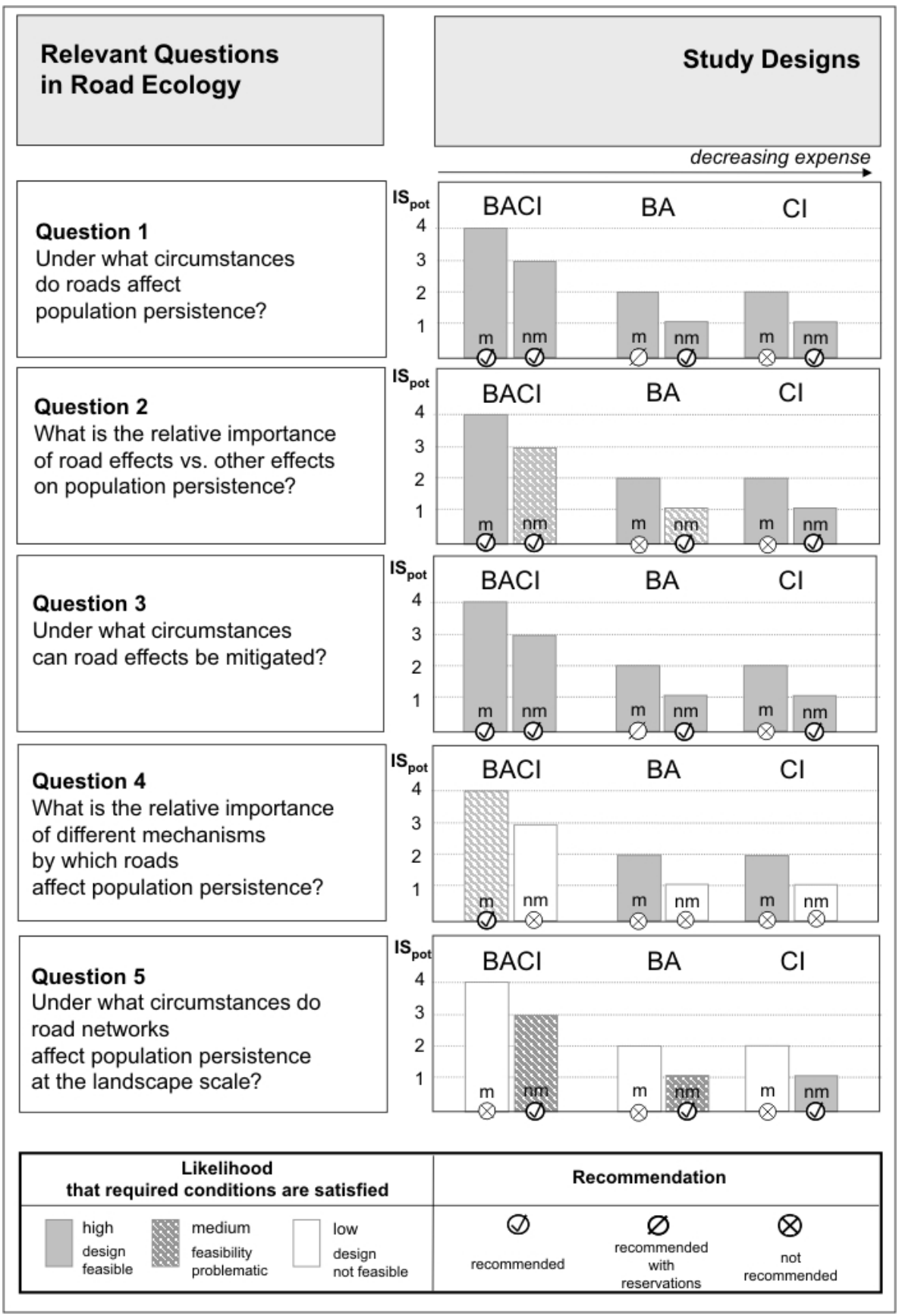




\section{The problem of extrapolation}

Rarely do the conditions under which the research was conducted completely match the conditions in which the research results are to be applied, and the greater the extrapolation, the lower the inferential strength of the study. Four main types of extrapolation occur in road ecology:

1. Spatial extrapolation occurs when either the research results at one site are used to make inferences about road effects at other sites or the results of a road ecology experiment in a small area, e.g., a 100-ha forest fragment, are used to make inferences about road effects in a larger area measuring, e.g., $1000 \mathrm{~km}^{2}$. In the first situation, it may not be possible to conduct the experiment at the sites of interest because of political or logistical concerns. In the second, it might be impossible to conduct the experiment on the required spatial scale because of time and resource constraints.

2. Temporal extrapolation occurs when the results of a short-term experiment lasting, e. g., 12 months are used to make inferences about the long-term response, e.g., population persistence. Of particular concern here is the possibility of time lags in the relationship between the impact, i.e., road, and response, i.e., population size (Findlay and Bourdages 2000). In such instances, extrapolation of a weak short-term effect would lead to an underestimate of the effect over the long term. However, temporal extrapolation is often necessary because it is rarely feasible to design a BACI or BA study that will last several decades.

3. Taxonomic extrapolation occurs when the results of studies of a single or a few representative focal species, i.e., umbrella species, are used to infer effects on other species or groups of species (Lambeck 1997, Lindenmayer et al. 2002, Caro et al. 2005, Ozaki et al. 2006). This is necessary when either the particular species of interest cannot be studied because of logistical or political constraints, or the objective is to develop principles about the effects of roads on wildlife in general but it is not feasible to study a large number of species.
4. Endpoint extrapolation occurs when the assessment endpoint is far away from the measurement endpoint. The assessment endpoint is the environmental value of actual interest; here, it is the probability of population persistence. The measurement endpoint is the response that is actually measured (Suter 1990, 1993). Because population viability cannot be directly measured, the attributes of the population that are known to be related to population viability, such as changes in population size over time, age structure, or number of roadkilled individuals, are estimated. Some measurement endpoints are more closely related to the assessment endpoint than others, thereby reducing extrapolation. For example, if the measurement endpoint is population trends over time and the researcher observes a declining trend following road construction, he is more confident in making a prediction about the effect of the road on population persistence than if the measurement endpoint is the number of road-killed animals (see the subsection on the current state of road ecology research).

\section{EXPERIMENTAL DESIGNS}

In this section, we describe a set of studies that vary in their inferential strength and feasibility for each of the focal questions asked above. We begin with question-specific discussions of potential beforeafter-control-impact (BACI) designs. We then move to a more general discussion of before-after (BA) and control-impact (CI) designs because the issues surrounding these designs are generic to all the questions.

\section{Before-after-control-impact designs}

Question 1: Under what circumstances do roads affect population persistence?

There are three general types of road BACIs (Fig. 2 ). In the road-construction BACI, the population is surveyed before and after road construction at sites at which a road was built and at control sites 
at which no road was built. In the road-modification BACI, the population is surveyed before and after an existing road is modified in some manner, e.g., expansion from two to four lanes or the installation of street lights, at road sites at which the modification occurred and at control road sites at which no modification occurred. In the roadremoval BACI, the population is surveyed before and after road removal or closure at sites at which removal occurred and at control sites at which the road was not removed.

A subtype of the road-construction BACI is the road-construction BDACI (before-during-aftercontrol-impact). Here, the population is surveyed before, during, and after road construction at sites at which a road was built and control sites at which no road was built. This study increases our knowledge about the (ir)reversibility of the effects that might occur during the road-construction phase, but may disappear after construction, e.g., the effects of noise from road construction.

All types of road BACIs require at least two sets of replicated sites (Fig. 3): (1) impact sites with road construction, modification, or removal and (2) control sites without such interventions. Control sites should be located outside the road effect zone of the planned road construction, modification, or removal (Reijnen and Foppen 1994) and should be as similar as possible to the impact sites with regard to land use, species composition and abundance, and particularly the habitat requirements of the species of interest. A measurement endpoint closely related to population persistence, e.g., abundance of the species of interest, should be sampled at multiple times before and after the intervention in both the control and impact sites. The population should be surveyed for long enough following the intervention to capture possible lag effects. This design can be implemented as a manipulative or a nonmanipulative BACI (Fig. 1).

\section{Question 2: What is the relative importance of road effects on population persistence?}

A modified design for a road-construction BACI is desirable for determining the relative importance of roads vs. some other impact. For example, if the other impact is pesticide use, the study should include (1) control areas without either impact, (2) impact sites with road construction but without pesticide use or with reduced use, and (3) impact sites without road construction but with pesticide use (Fig. 4). Additional sites with both roads and pesticide use address the issue of potential interactions between stressors. If, for example, roads have a larger effect on wildlife populations than does pesticide exposure, the difference between before and after should be greater for the contrast between control and road-impact sites than for the contrast between control and pesticideimpact sites. Impacts should ideally commence simultaneously, to avoid the confounding effects of different characteristic response times for different stressors. Control and impact sites should be replicated, with multiple sampling times both before and after the intervention(s).

This design can be implemented as a manipulative or a nonmanipulative BACI (Fig. 1). However, the nonmanipulative study requires sites at which the road impact and the pesticide impact commenced simultaneously, and for which data were available on the population both before and after the impacts. Because it would be extremely difficult to find such sites, this design has low feasibility (Fig. 1).

\section{Question 3: Under what circumstances can road effects be mitigated?}

We recognize three general types of mitigation BACI designs. In the mitigation-construction $\mathrm{BACI}$, the population is surveyed before and after the construction of a mitigation measure at sites at which a mitigation measure was built and at sites without mitigation measures. In the mitigationmodification BACI, the population is surveyed before and after an existing mitigation strategy is modified in some manner, at both the control and impact sites. In the mitigation-removal BACI, the population is surveyed before and after the removal of a mitigation measure, at both control and impact sites.

There are three possible mitigation-construction BACI designs. The first determines whether new roads that are built with mitigation measures in place have a smaller effect on the population of interest than do roads built without mitigation measures. Here, populations are compared at (1) control sites with no roads, (2) control sites with roads with no mitigation measures, and (3) "impact" sites with roads and mitigation measures. The measurement endpoint is sampled before and after the roads with and without mitigation measures are constructed. The results will be useful in designing new roads. 
Fig. 2. Three types of road before-after-control-impact (BACI) study designs. An elaboration of the road-construction BACI is the BDACI design (before-during-after-control-impact), in which effects may be evaluated during the road construction phase.
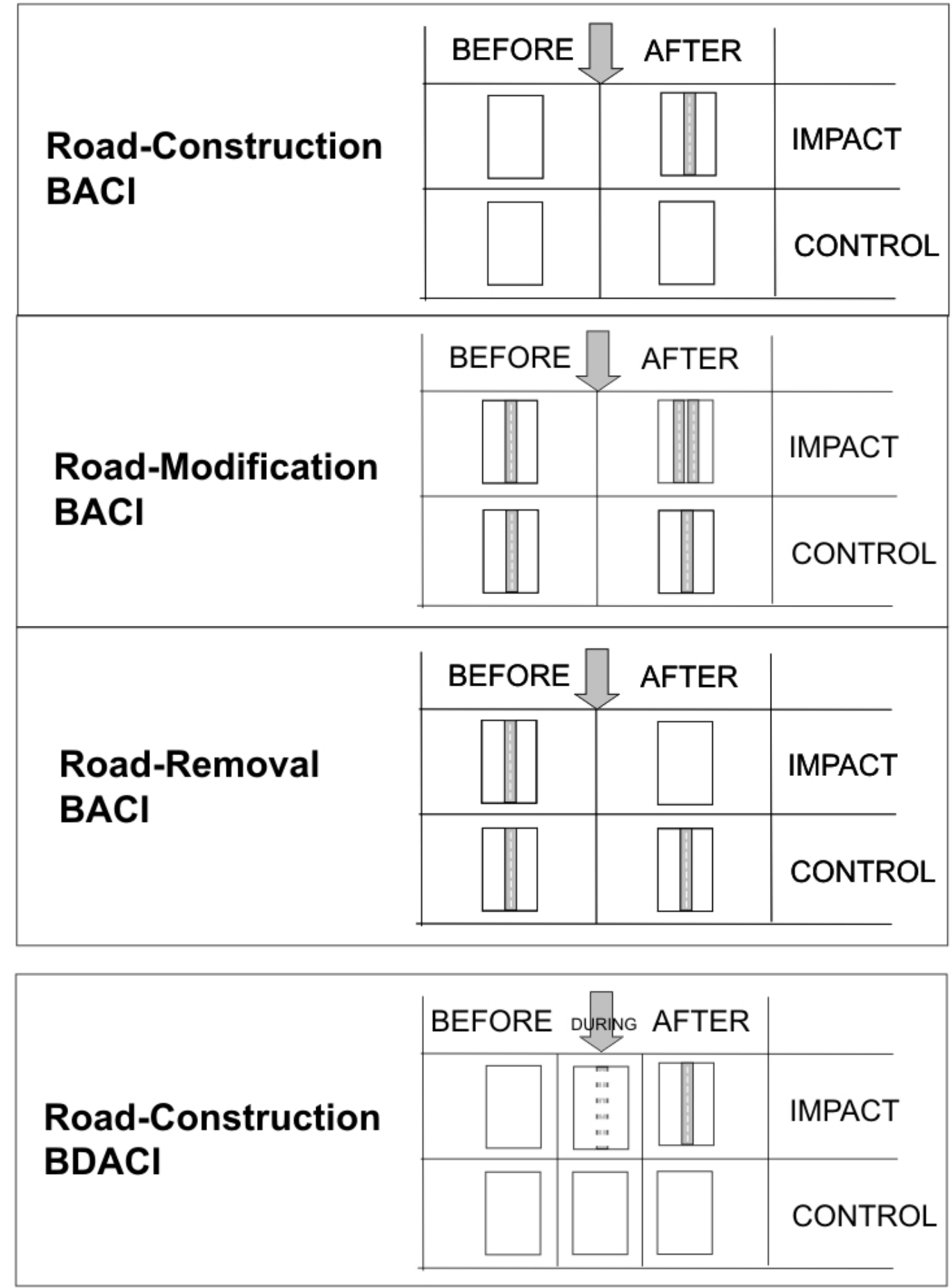
Fig. 3. Study designs and hypothetical results for Question 1: Under what circumstances do roads affect population persistence? We use a road-construction before-after-control-impact (BACI) study design as an example (see Fig. 2). The study types include before-after-control-impact (BACI), before-after (BA), and control-impact (CI) designs. The correlation study is a subtype of the CI design.

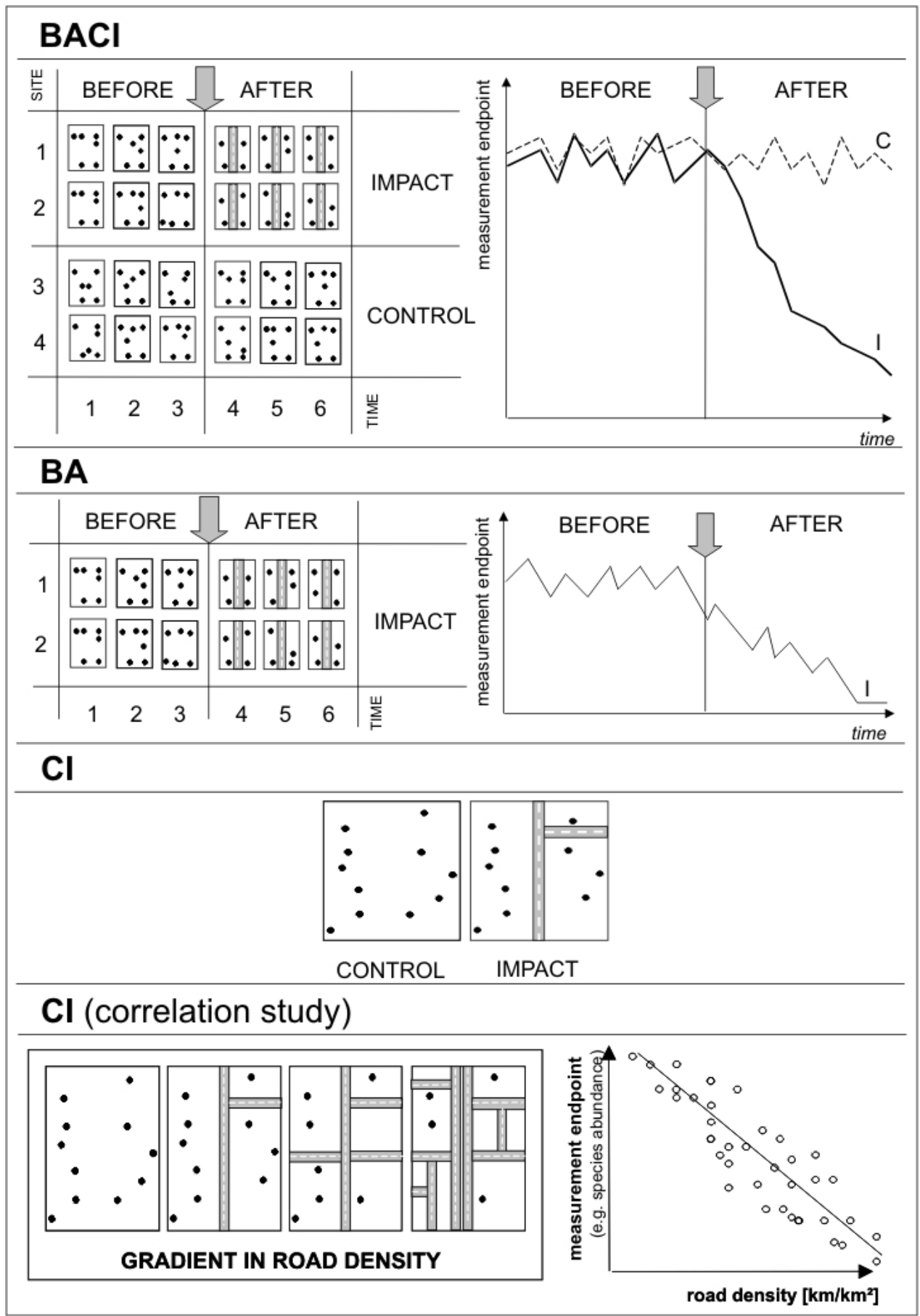


Fig. 4. Study designs and hypothetical results for Question 2: What is the relative importance of road effects on population persistence? The study types include before-after-control-impact (BACI), beforeafter (BA), and control-impact (CI) designs. The correlation study is a subtype of the CI design.

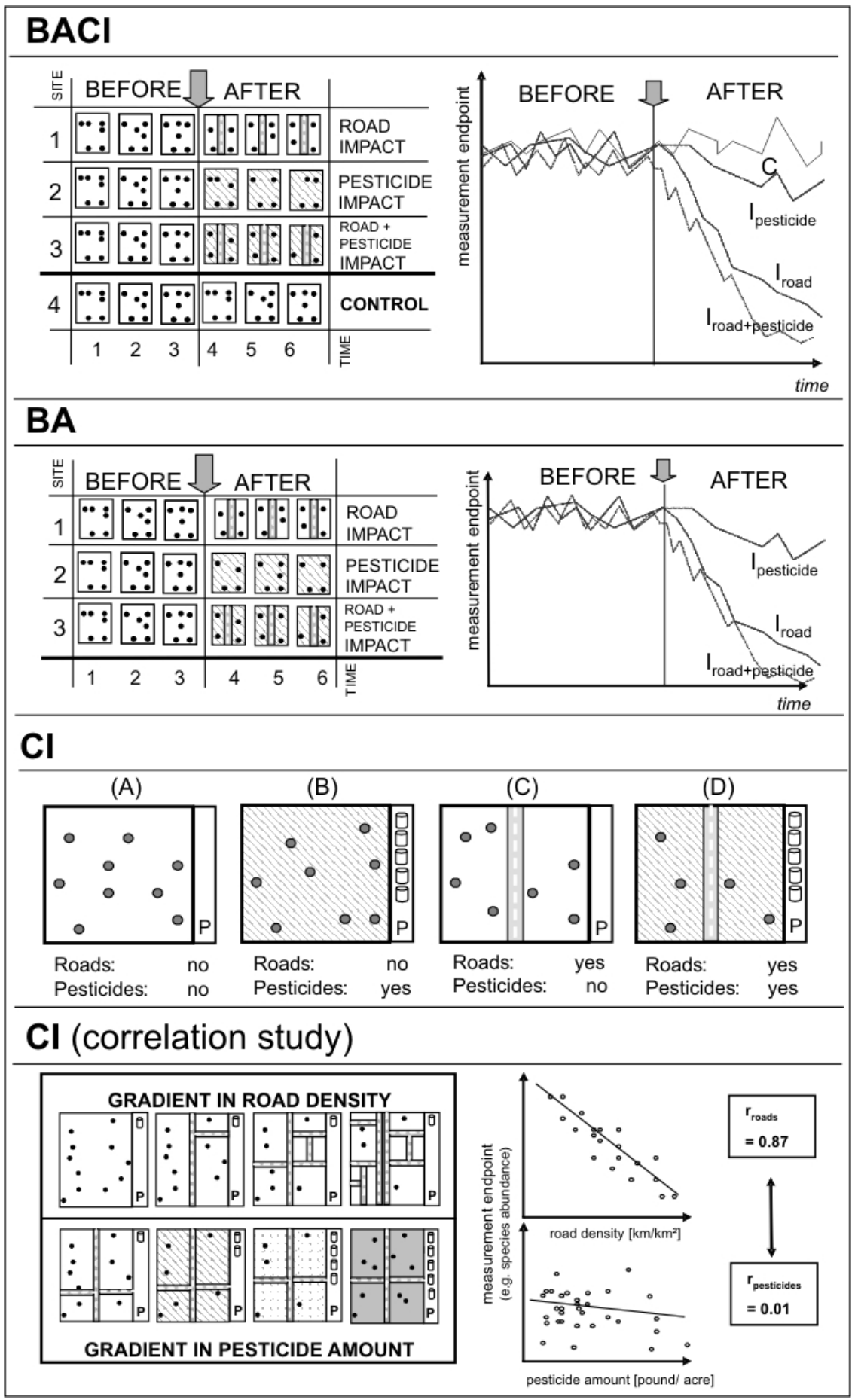


The second design determines whether mitigation measures can restore a population to viability after a road has already been affecting it for some time. This can be answered by the mitigation-construction BDACI (before-during-after-control-impact). At the impact site, the road is first constructed without a mitigation measure, and then some time later a mitigation measure is added (Fig. 5). The population is sampled before road construction, after road construction without mitigation, i.e., during sampling, and after the addition of the mitigation measure (Fig. 5). This design requires two control sites: one with no road and one with a road without mitigation. The before-during comparison provides information on the size of the road effect; the duringafter comparison provides an estimate of the extent to which the road effect is mitigated. This design is feasible as a manipulative or nonmanipulative study. However, it is particularly susceptible to problems of time-scale extrapolation (see the subsection on the problems of extrapolation), because both road and mitigation effects are likely to show lagged responses.

A simpler mitigation-construction BACI is obtained by choosing only sites that already have roads on them and sampling the population before and after the addition of the mitigation measure. This design will indicate whether the mitigation measure is effective, but not whether the road effect is fully mitigated. However, it can provide valuable information for defragmentation programs aimed at mitigating the impacts of the current road network (Van der Grift 2005).

It is also possible to compare the effectiveness of two mitigation measures such as fences and passageways. In addition to the sites mentioned above, sites with the road and the second mitigation measure are also required. Additional sites with the road and both mitigation measures would allow evaluation of the combined effects of both mitigation measures.

Question 4: What is the relative importance of the different mechanisms by which roads affect population persistence?

Here the general approach is to establish conditions under which only a single mechanism is possible at one time or in one context. To illustrate, we discuss study designs that distinguish the relative effects of mortality vs. movement barriers, but the same designs could be applied to any pair of effects, e.g., mortality vs. disturbance, disturbance vs. movement barrier, one type of disturbance vs. another type of disturbance, etc. Answering this question requires an elaborate and rather artificial manipulative BACI design. It is not possible to answer this question in any type of nonmanipulative study (Fig. 1).

The BACI design requires five sets of replicated sites (Fig. 6): (1) control sites containing no roads and no movement barriers at which movement is unhindered and there is no road mortality, (2) sites with no roads that incorporate fences as movement barriers, (3) sites with no roads and no fences at which mortality is simulated by removing individuals from the population at a rate equal to estimated traffic mortality, (4) sites with no roads that incorporate fences at which mortality is again simulated by removing animals, and (5) sites with roads but no fences and no simulated mortality.

Measurement endpoints are assessed before and after treatment at all sites. The magnitude of the road effect mechanism of mortality or barrier is estimated as the difference between the control sites (type 1) and the sites with no roads in which the road effect is simulated (types 2 and 3). Including sites with both simulated effects (type 4) makes it possible to estimate their combined effect. Finally, the difference between type- 4 sites and the sites with an actual road present (type 5) allows us to estimate the size of all additional road effects such as traffic noise and habitat disturbances.

This design is very difficult to implement and therefore has low feasibility (Fig. 1). First, because the different mechanisms of mortality and barrier, in our example, may take different lengths of time to affect population persistence, the populations will need to be monitored for a sufficient time period to estimate their relative effects (Jaeger and Fahrig 2001). Second, simulating road mortality requires a pilot study to estimate road mortality and its demographic effects. Third, because roads are generally not complete barriers to movement, the permeability of the barrier simulation will need to be controlled experimentally by moving some animals across the fence. This in turn will require another pilot study designed to estimate movement rates. Finally, because the mechanisms related to mortality and barrier effect will vary with road type, traffic volume, and season, both pilot studies and the BACI study itself should be conducted under a range of different conditions. 
Fig. 5. Study designs and hypothetical results for Question 3: Under what circumstances can road effects be mitigated? The study types include before-after-control-impact (BACI), before-after (BA), and control-impact $(\mathrm{CI})$ designs.

\section{BDACI}

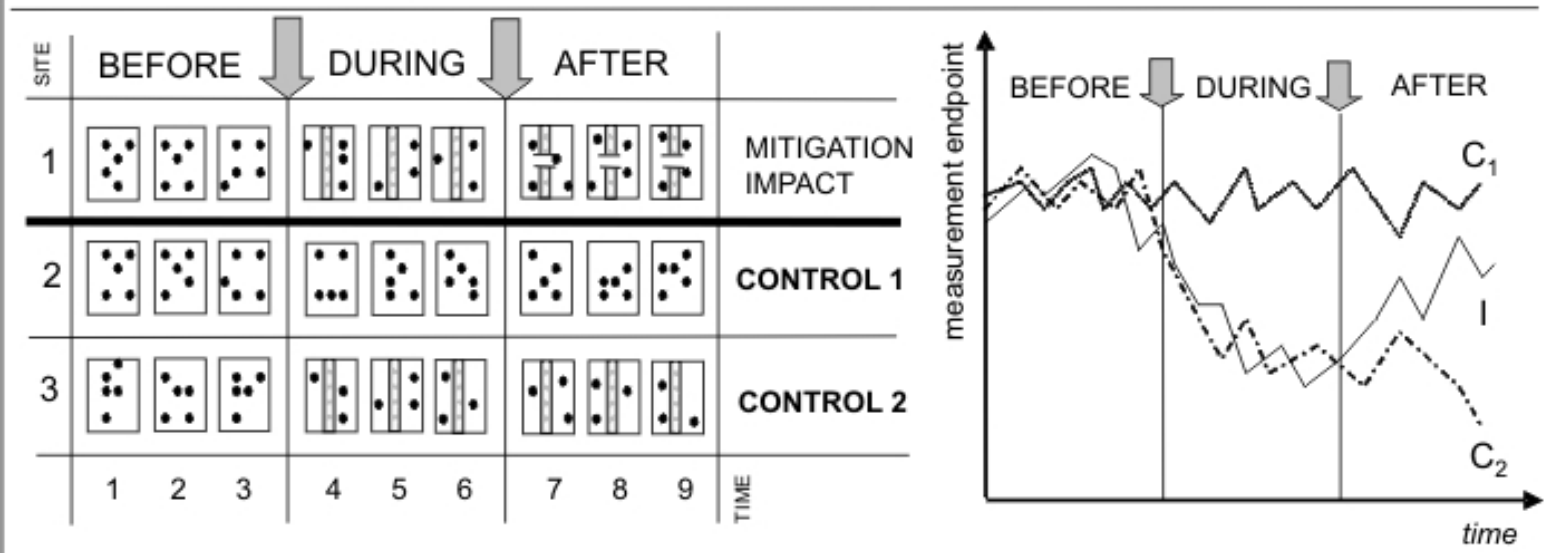

"This BDACl design addresses the question whether mitigation help s to enhance population viability after chronic (prolonged) exposure. Exclusion of the 'during' (D) design element is aimed at determining whether new roads that are built with mitigation measures in place have a smaller effed on the population of interest than roads that are built without mitigation measures.

\section{BDA}

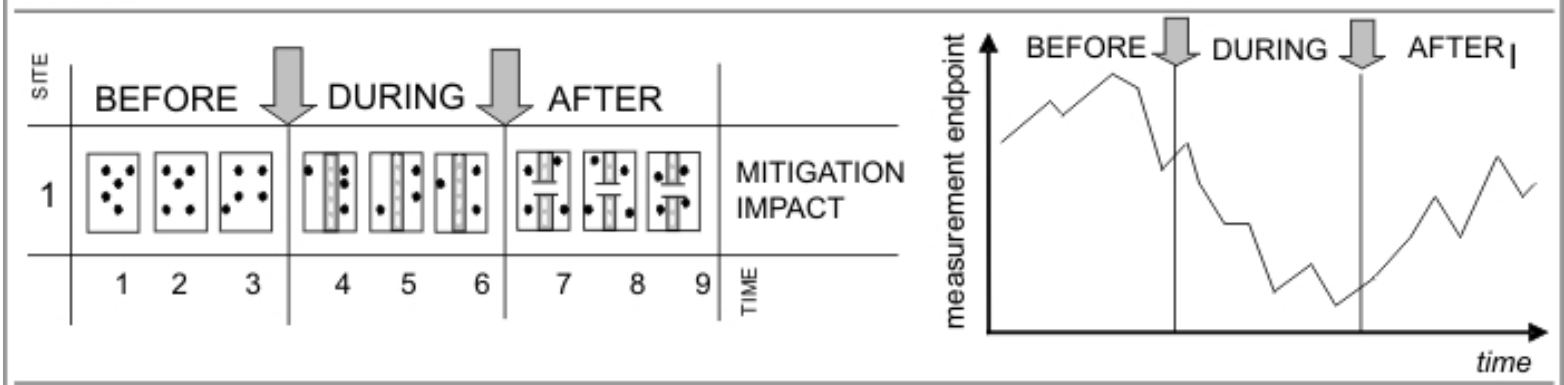

\section{Cl}

(A)

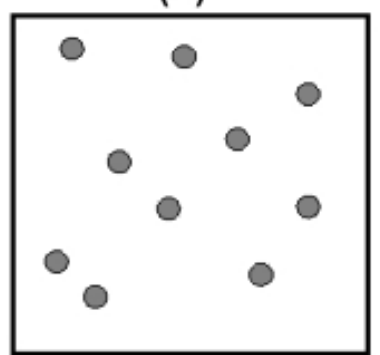

Control I: no road
(B)

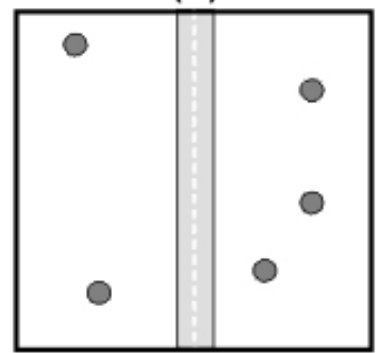

Control II: road without mitigation
(C)

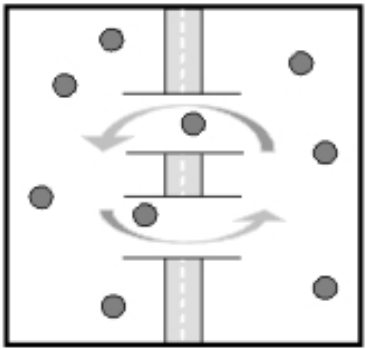

Mitigation impact: road + mitigation 
Fig. 6. Study designs and hypothetical results for Question 4: What is the relative importance of the different mechanisms by which roads affect population persistence? The study types include beforeafter-control-impact (BACI), before-after (BA), and control-impact (CI) designs.

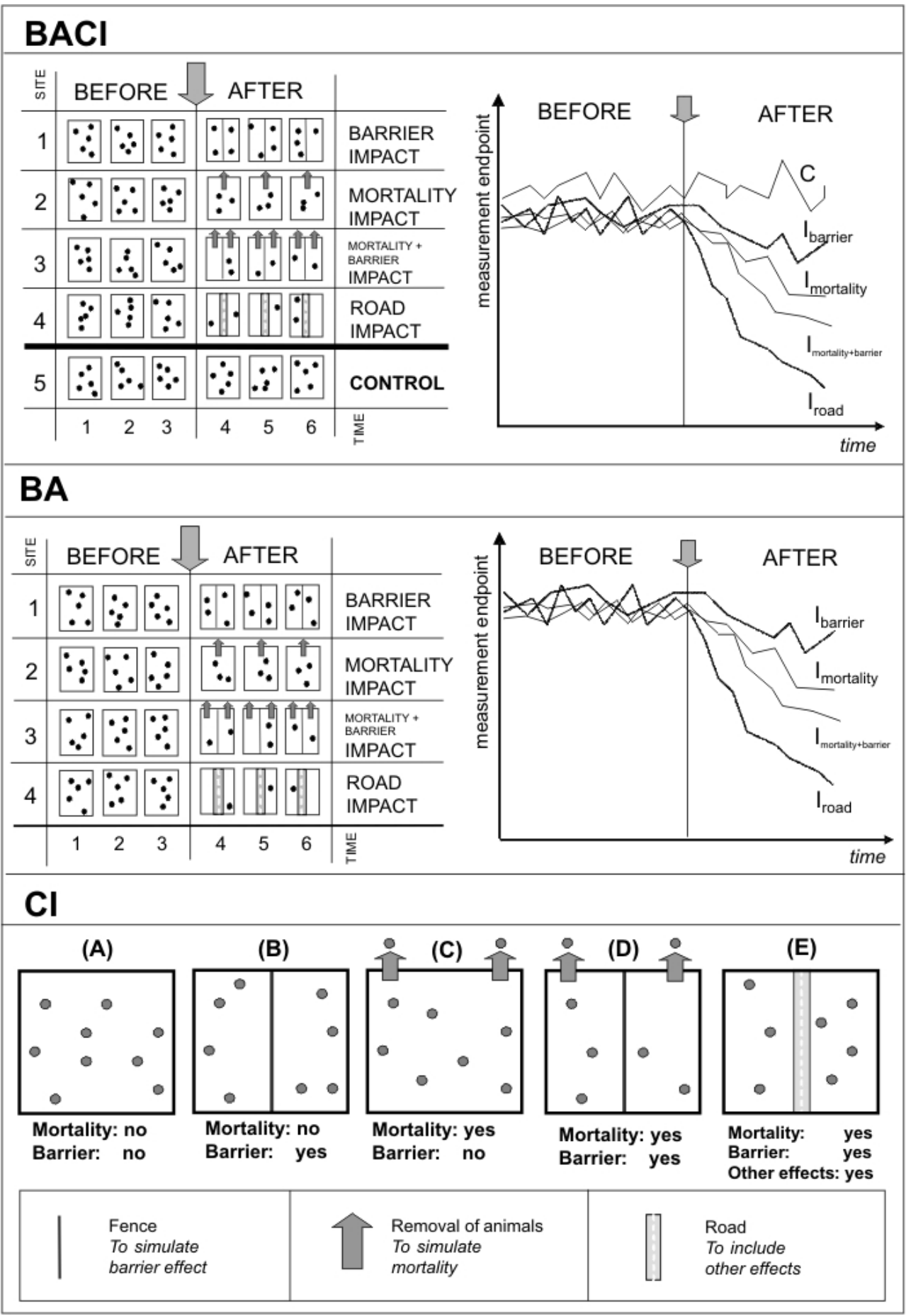


Question 5: Under what circumstances do road networks affect population persistence at the landscape scale?

At the landscape scale, three types of nonmanipulative BACIs are possible (see also Fig. 2): a road-construction BACI in which the density of the road network has increased over time, a roadmodification BACI in which road density has been constant but traffic volume has increased or network configuration has changed, and a road-removal $\mathrm{BACI}$ in which roads have been removed from the network.

The road-construction BACI requires at least two sets of sites (Fig. 7): (1) impact sites at which the road network has increased over time and (2) control sites with no increase in network density over time. The sites and the landscapes should be as similar as possible, particularly with regard to the habitat requirements of the species observed. Control and impact sites should be replicated, and population data must be available before and after the changes to the road network at all the sites, most likely from existing long-term, large-scale programs for monitoring wildlife populations.

Manipulative experiments will generally not be possible on the scale of whole road networks (Fig. 1). Nonmanipulative BACIs will have low feasibility for two main reasons: (1) the difficulty in finding replicated control and impact landscapes in which other factors affecting population persistence, e.g., extension of settlements and agricultural development, are similar over the entire time span of the study and (2) the requirement that there be reasonably accurate, systematic wildlife population data extending over the entire spatial and temporal span of the study. The larger the required landscapes because of, for example, large dispersal distances of target species, the more difficult it will be to find comparable nonoverlapping landscapes and wildlife data.

\section{Before-after designs}

If appropriate control sites for a BACI are lacking, a before-after (BA) design may be used. Here, substantial differences in the selected measurement endpoints before and after the intervention, e.g., road construction or mitigation measures, indicate an effect on population persistence (see the subsection on the hierarchy of designs).
A manipulative BA design gives some control over the design of the manipulation itself, because the researcher is conducting the study in the knowledge that the manipulation, e.g., road construction, will occur. We do not recommend manipulative BA designs, because, given the expense and time required for them, it is worth including control sites and performing the full BACI to realize the maximum possible inferential strength, especially for questions requiring a large amount of prospective planning (Questions 2 and 4). However, there may be situations in which there is no choice of impact sites, e.g., because of political concerns, and appropriate control sites may simply not be available (Questions 1 and 3). In this case a manipulative BA is the design of choice. At a large scale, a manipulative BA is not feasible (Question $5)$.

Nonmanipulative designs are those for which the researcher has information on endpoints collected both before and after the intervention but had no hand in the intervention itself. Because of the retrospective character of the study, it is possible that no appropriate control sites can be found, and in this case a nonmanipulative BA is the design of choice (Fig. 1). The feasibility of nonmanipulative designs might be problematic or impossible for the same reasons outlined above in the description of BACI designs.

\section{Control-impact designs}

If preintervention data are unavailable, a controlimpact (CI) design can be used in which the population is surveyed in (1) sites with and without a road present (Fig. 3), (2) sites representing two uncorrelated gradients of road density and another stressor such as pesticide use (Fig. 4), (3) sites with and without one or more mitigation measures (Fig. 5), and (4) sites spanning a gradient of road densities or traffic volumes, i.e., a correlation study (Fig. 7).

We do not recommend manipulative CI studies for any focal question, simply because, if a prospective manipulative $\mathrm{CI}$ is possible, there is little excuse for not monitoring both before and after construction, in which case the study incorporates all elements of the BACI design (Fig. 1). At a large scale, a manipulative $\mathrm{CI}$ is simply not feasible. The nonmanipulative $\mathrm{CI}$ design is recommended for all of the above questions except the one related to the relative importance of the different mechanisms by 
Fig. 7. Study designs and hypothetical results for Question 5: Under what circumstances do road networks affect population persistence at the landscape scale? The study types include before-aftercontrol-impact (BACI), before-after (BA), and control-impact (CI) designs. The correlation study is a subtype of the CI design.

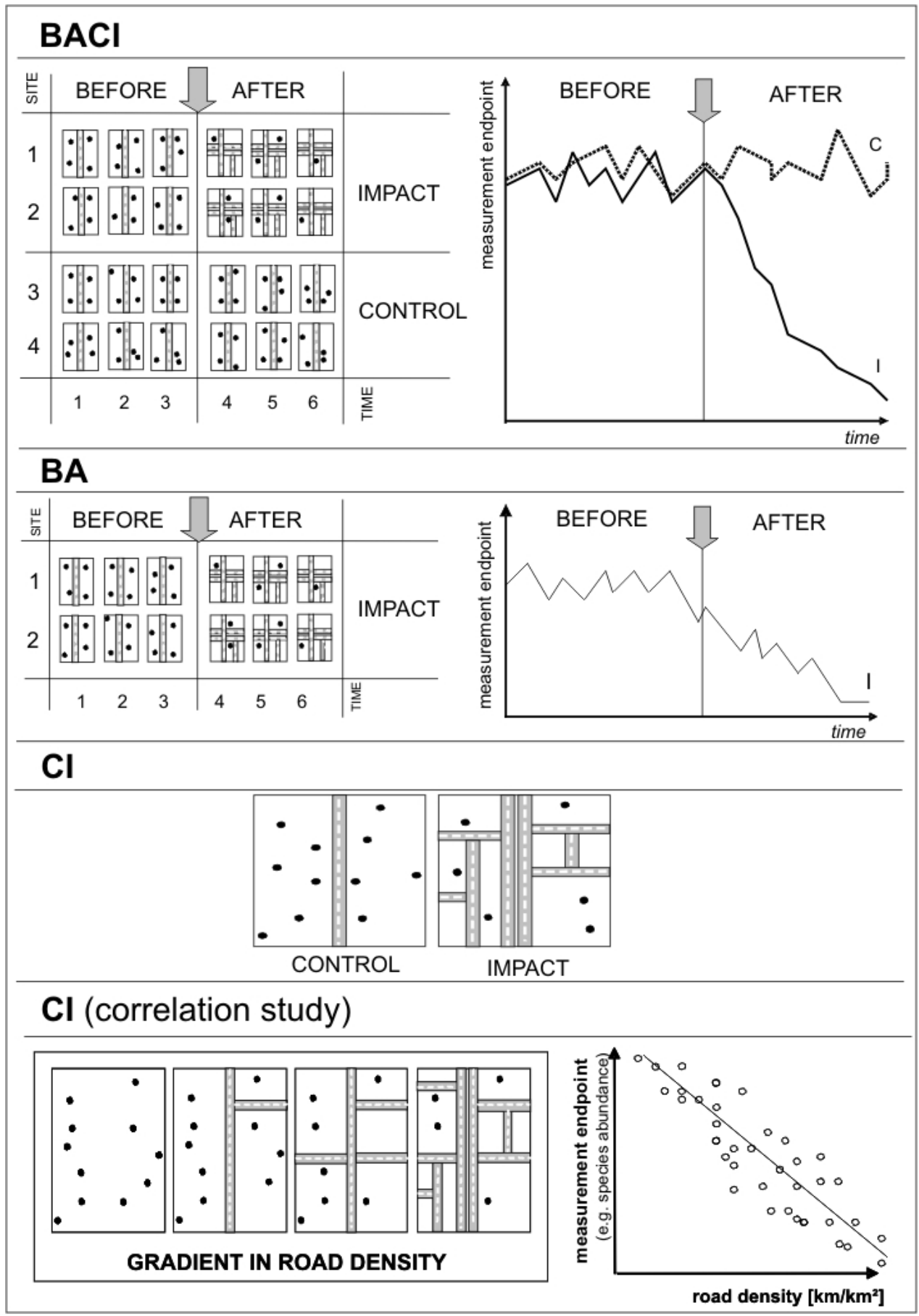


which roads affect population persistence, because, retrospectively, it is highly unlikely that the artificial conditions required for the design of that question will be satisfied (Fig. 6).

\section{DISCUSSION}

\section{Current state of road ecology research}

Past studies in road ecology generally have low inferential strength for two main reasons. First, the usual measurement endpoints are typically well removed from the quantity of interest, namely, population viability and persistence. One of the most common measurement endpoints is movement across roads (e.g., Mader 1984, Merriam et al. 1989, Brody and Pelton 1989) and/or through mitigation structures (e.g., Clevenger and Waltho 2000, 2005). Although movement is an important component of population dynamics, its predictive value with respect to population persistence is low. For example, although roads have a negative effect on the movement of small mammals (Mader 1984), the density of the population of small mammals is sometimes positively associated with roads, possibly because of the negative effect of roads on predator populations (T. D. M. Rytwinski and L. Fahrig, unpublished manuscript) or alterations in road site habitats in favor of small mammals. Therefore, inferring impacts on population persistence from the effects on movement rates is fraught with uncertainty. Similar problems of inference arise from estimates of road-induced mortality, another common measurement endpoint in road ecology (e.g., Lodé 2000, Baker et al. 2004). Inferring effects on population persistence from the numbers of road-killed individuals is very tenuous and requires information on population size, variability, and the likelihood of compensatory mechanisms such as reductions in other mortality sources or increases in reproduction in response to road mortality.

Second, most studies are control-impact (CI) designs without before-after (BA) data (e.g., Ballon 1986, Mech et al. 1988, Findlay and Houlahan 1997, Clarke et al. 1998, Vos and Chardon 1998, Findlay and Bourdages 2000, Carr and Fahrig 2001). Although these studies have produced some suggestive results, the inferential strength of CI designs is always lower than that of BACI designs and usually lower than that of BA designs. Without data on endpoints from before the impact, one cannot rule out the hypothesis that the difference between the control and impact sites is because of pre-existing differences among the sites that are unrelated to the road.

A science that is built on studies of generally low inferential strength is problematic. The lower the inferential strength of the studies, the more likely that the collection of such studies will produce apparently conflicting results even if the underlying hypotheses are generally true. Not only does this create uncertainty, but it also results in considerable effort being expended to "resolve" apparently contradictory results, when in fact the contradiction may simply reflect incorrect inferences arising from poor experimental designs. This was underlined by Danielson and Hubbard (1998) in their review of three studies that evaluated the effectiveness of Swareflex reflectors in reducing vehicle wildlife collisions; one of these studies used a BACI design (Gladfelter 1984), and the other two used a CI design (Schafer and Penland 1985, Reeve and Anderson 1993). Here, the contradictory results that resulted from poor study designs caused state transportation agencies to expend considerable resources repeating the research or implementing mitigation measures that had not really been proven to be effective (Danielson and Hubbard 1998).

Inferential strength matters, in particular, in environmental impact assessment (EIA) studies, in which research "meets" decision making. Decision makers are legally obligated to commission EIAs to estimate the potential impacts of proposed roads and the extent to which these expected impacts can be mitigated. A review was conducted in the UK to determine if the EIAs for proposed roads met the minimum standard of scientific rigor necessary to make useful inferences (Treweek et al. 1993, Byron et al. 2000). It highlighted certain shortcomings in the EIA process. For instance, the studies did not differentiate between the relative importance of different road effects, and they did not collect data from the period after the construction of roads or mitigation measures. The reviewers concluded that EIA studies were not of an appropriate type to capture relevant ecological information. However, decisions about road siting and mitigation measures are based on the results of these studies, and the lower the inferential strength, the less certain one can be that expected impacts will indeed be observed and can really be mitigated. The reviewers concluded that the scientific basis needed to be improved, because much survey effort is wasted on 
studies generating information that contributes little to the decision-making process.

\section{Implications}

The experimental design issues raised in this paper have implications for research scientists, scientific funding organizations, planners, and decision makers. For researchers, the implications are straightforward: when designing studies on the effects of roads or the mitigation of road effects, they should strive toward the maximum possible inferential strength, given existing constraints. When practical considerations dictate a study design of lower inferential strength than is desirable, it is important that the results from such studies be interpreted with caution, and that the resulting conclusions be appropriately tempered. It is possible that definitive experiments with high inferential strength carried out over the relevant temporal and spatial scales cannot feasibly be undertaken by individual researchers. Instead of continuing to undertake isolated studies in the hope that the sheer volume of them may compensate for the absence of definitive studies, it seems advisable to combine forces, resources, and expertise in a study that has high inferential strength and permits generalizable and robust conclusions.

For scientific funding organizations, the implications are equally straightforward: there is, in general, a positive correlation between the inferential strength of a study and the resources required to carry it out. As such, funding agencies cannot insist that the same study meet the mutually exclusive goals of high inferential strength and low cost. Moreover, we argue that an investment in a good experiment is actually more cost-effective than a series of "shotin-the-dark" attempts to fix a problem. An efficient experiment is not simply defined as a cheap experiment; rather, it is an experiment that derives the required information for the least expenditure of resources (Barker 1994). We have identified feasible study designs of reasonably high inferential strength (Fig. 1); a funding agency will maximize the scientific value and cost-effectiveness of research by giving high priority to these types of studies. The demand for such studies is of some urgency, because, even with a willingness to commit resources, future research may be limited by the fact that few landscapes exist in which to undertake the necessary experiments.
For planners and decision makers, the most important issue is that constraints on feasibility and costs will necessarily limit inferential strength. For example, for questions concerned with landscapescale ecological effects and long-term consequences, the inferential strength of any feasible study will always be comparatively low. Study designs of lower inferential strength, such as the nonmanipulative CI design, may be the best one can do in these situations. Consequently, it is inevitable that the uncertainty associated with any conclusion will necessarily be high. Nevertheless, the most pressing policy and management issues are generally not at the local, but at the landscape scale (National Research Council 2005). It is a cruel irony in road ecology that, the more important the question, the more uncertainty is associated with the answers that road science will be able to provide.

For road ecology, and especially those issues relevant to landscape-level planning and management, a strong weight of evidence, i.e., scientific proof, is unattainable in practice, and to insist upon it is tantamount to discounting all the scientific research that is likely to be conducted now or in the foreseeable future. Nevertheless, decisions must be made. For such questions, the standard of proof required for consideration in the planning process must be comparatively low, and decision makers must embrace general normative decision-making principles and approaches for judgment under uncertainty. Examples are the precautionary principle and the establishment of quantitative limits or objectives to limit road density or the degree of landscape fragmentation; both require transdisciplinary discussions among scientists, the public, and decision makers (see Jaeger and Scheringer 1998, Böschen et al. 2001, Jaeger 2002). The task of the road ecologist is to provide scientific answers with the highest inferential strength possible; the task of decision makers is to recognize and make decisions in the face of the inherent limitations and uncertainties in these answers.

Responses to this article can be read online at: http://www.ecologyandsociety.org/voll2/iss 1/art11/responses/ 


\section{Acknowledgments:}

This paper began through late-night discussions during the "Landscape-scale Effects of Roads on Biodiversity" workshop in November 2005, held at the Castle of Rauischholzhausen, and funded by the German Research Foundation (DFG - SFB 299). After the workshop, work on this paper continued through a workshop in Ottawa, funded in part by a Natural Sciences and Engineering Research Council of Canada grant to L. Fahrig. N. Klar, and I. Roedenbeck are supported by fellowships from the Dr. Joachim und Hanna Schmidt Stiftung für Umwelt und Verkehr and the German Environmental Foundation (DBU). E. van der Grift was supported by the Dutch Ministry of Agriculture, Nature and Food Quality, the Dutch Ministry of Transport and Public Works, and the research programme 'KENNISBASIS' of Wageningen University and Research Centre. We are grateful to S. Kostrzewa, $W$. Köhler, and the members of the Landscape Ecology Laboratory at Carleton University for comments on an earlier version of this paper.

\section{LITERATURE CITED}

Baker, P. J., S. Harris, C. P. J. Robertson, G. Saunders, and P. C. L. White. 2004. Is it possible to monitor mammal population changes from counts of road traffic casualties? An analysis using Bristol's red foxes Vulpes vulpes as an example. Mammal Review 34:115-130.

Ballon,P. 1986. Bilan technique des aménagements réalisés en France pour réduire les impacts des grandes infrastructures linéaires sur les ongulés gibiers. Bulletin Mensuel ONC 104:33-39.

Barker, T. B. 1994. Quality by experimental design. Marcel Dekker, New York, New York, USA.

Bernstein, B. B., and J. Zalinski. 1983. An optimum sampling design and power test for environmental biologists. Journal for Environmental Management 16:35-43.

Böschen, S., M. Scheringer, and J. Jaeger. 2001: Wozu Umweltforschung? Über das Spannungsverhältnis zwischen Forschungstraditionen und umweltpolitischen Leitbildern. Teil II. Zum Leitbild "Reflexive Umweltforschung." GAIA 10(3):203-212.

Bratzel, S., and R. Tellermann. 2005. Mobilität und Verkehr. Informationen zur politischen Bildung 287(2):44-51.

Brody, A. J., and M. R. Pelton. 1989. Effects of roads on black bear movements in Western North Carolina. Wildlife Society Bulletin 17:5-10.

Bundesamt für Naturschutz. 1999. Daten zur Natur 1999. Landwirtschaftsverlag, Bonn, Germany.

Byron, H. J., J. R. Treweek, W. R. Sheate, and S. Thompsen. 2000. Road developments in the UK: an analysis of ecological assessment in environmental impact statements produced between 1993 and 1997. Journal of Environmental Planning and Management 43(1):71-97.

Caid, N., P. Crist, R. Gilbert, and P. Wiederkehr. 2002. Environmentally sustainable transport: concept, goal and strategy-the OECD's EST Project. Proceedings of the Institution of Civil Engineers, Transport 153(4):219-226.

Caro, T., J. Eadie, and A. Sih. 2005. Use of substitute species in conservation biology. Conservation Biology19(6):1821-1826.

Carr, L. W., and L. Fahrig. 2001. Effect of road traffic on two amphibian species of different vagility. Conservation Biology 15(4):1071-1078.

Chamberlin, T. C. 1965 . The method of multiple working hypotheses. Science 148:754-758.

Clarke, G. P., P. C. L. White, and S. Harris. 1998. Effects of roads on badger Meles meles populations in south-west England. Biological Conservation 86:117-124.

Clevenger, A. P. 2002. Mitigation for wildlife. Pages 139-167 in R. T. T. Forman, D. Sperling, J. A. Bissonette., A. P. Clevenger, C. D. Cutshal, V. H. Dale, L. Fahrig, R. France, C. R. Goldman, K. Haenue, J. A. Jones, F. J. Swanson, T. Turrentine, and T. C. Winter. Road ecology-science and solutions. Island Press, Washington, D.C., USA.

Clevenger, A. P., and N. Waltho. 2000. Factors influencing the effectiveness of wildlife underpasses 
in Banff National Park, Alberta, Canada. Conservation Biology 14(1):47-56.

Clevenger, A. P., and N. Waltho. 2005. Performance indices to identify attributes of highway crossing structures facilitating movement of large mammals. Biological Conservation 121:453-464.

Danielson, B. J., and M. W. Hubbard. 1998. A literature review for assessing the status of current methods of reducing deer-vehicle collisions. Report prepared for the Iowa Department of Transportation and Iowa Department of Natural Resources, Iowa, USA. Available online at: http://www.dot.state.ia.us/ crashanalysis/data/environment/animal/

isudeervehiclestudyfordotdnr.pdf.

Findlay, C. S., and J. Bourdages. 2000. Response time of wetland biodiversity to road construction on adjacent lands. Conservation Biology 14(1):86-94.

Findlay, C. S., and J. Houlahan. 1997. Anthropogenic correlates of species richness in southeastern Ontario wetlands. Conservation Biology 11(4):1000-1009.

Forman, R. T. T. 1995. Land mosaics: the ecology of landscapes and regions. Cambridge University Press, Cambridge, UK.

Forman, R.T.T. 2000. Estimate of the area affected ecologically by the road system in the United States. Conservation Biology 14(1):31-35.

Forman, R. T. T., D. Sperling, J. A. Bissonette., A. P. Clevenger, C. D. Cutshal, V. H. Dale, L. Fahrig, R. France, C. R. Goldman, K. Haenue, J. A. Jones, F. J. Swanson, T. Turrentine, and T. C. Winter. 2002. Road ecology-science and solutions. Island Press, Washington, D.C., USA. [ ERRATUM]

Foster, R. K., P. Vecchia, and M. H. Repacholi. 2000. Science and the precautionary principle. Science 288(5468):979-981.

Goldstein, B. D., and R. S. Carruth. 2004. Implications of the precautionary principle: Is it a threat to science? International Journal for Occupational and Environmental Health 17 (1):153-161.

Gladfelter, L. 1984. Effect of wildlife highway warning reflectors on deer-vehicle accidents. Iowa
Highway Research Board Project HR-210. Iowa Department of Transportation, Ames, Iowa, USA.

Glitzner, I., P. Beyerlein, C. Brugger, F. Egermann, W. Paill, B. Schlögel, and F. Tataruch. 1999. Literaturstudie zu anlage- und betriebsbedingten Auswirkungen von Strassen auf die Tierwelt. Endbericht. Magistrat der Stadt Wien, Abteilung 22 - Umweltschutz. G5 - Game-Management, Graz, Austria.

Green, R. H. 1979. Sampling design and statistical methods for environmental biologists. John Wiley, New York, New York, USA.

Iuell, B., G. J. Bekker, R. Cuperus, J. Dufek, G. Fry, C. Hicks, V. Hlavác, V. Keller, B. Rosell, T. Sangwine, N. Tørsløv, and B. I. M. Wandall, editors. 2003. Wildlife and traffic: a European handbook for identifying conflicts and designing solutions. KNNV Publishers, Brussels, Belgium.

Jackson, S. D. 2000. Overview of transportation impacts on wildlife movement and populations. Pages 7-20 in T. A. Messmer and B. West, editors. Wildlife and highways: seeking solutions to an ecological and socio-economic dilemma. The Wildlife Society. Available online at: http://www.u mass.edu/nrec/pdf files/tws overview ms.pdf.

Jaeger, J. A. G. 2002. Landschaftszerschneidung. Eugen Ulmer, Stuttgart, Germany.

Jaeger, J. A. G., and L. Fahrig. 2001. Modelling the effects of road network patterns on population persistence: relative importance of traffic mortality and 'fence effect.' Pages 298-312 in G. Evink, editor. Proceedings of the 2001 International Conference on Ecology and Transportation (ICOET). 24-28 September 2001, Keystone Colorado. Available online at: http://www.icoet.net/ downloads/ICOET2001ProceedingsPrintVersion.pdf

Jaeger, J. A. G., and L. Fahrig. 2004. Effects of road fencing on population persistence. Conservation Biology 18(6): 1651-1657.

Jaeger, J. A. G., and M. Scheringer. 1998. Transdisziplinarität: Problemorientierung ohne Methodenzwang. GAIA 7(1):10-25.

Kilgo,J. C., R. F. Labisky, and D. E. Fritzen. 1998. Influences of hunting on the behavior of white- 
tailed deer: implications for conservation of the Florida panther. Conservation Biology 12:1359-1364.

Lambeck, R. J. 1997. Focal species: a multi-species umbrella for nature conservation. Conservation Biology 11(4):849-856.

Lindenmayer, D. B., A. D. Manning, P. L. Smith, H. P. Possingham, J. Fischer, I. Oliver, and M. A. McCarthy. 2002. The focal-species approach and landscape restoration: a critique. Conservation Biology 16(2):338-345.

Lodé, T. 2000. Effect of a motorway on mortality and isolation of wildlife populations. Ambio 29 (3):163-166.

Mader, H. J. 1984. Animal habitat isolation by roads and agricultural fields. Biological

Conservation 29:81-96.

McLellan, B. N., and D. M. Shackleton. 1988. Grizzly bears and resource-extraction industries: effects of roads on behaviour, habitat use and demography. Journal of Applied Ecology 25 (2):451-460.

Mech, L. D., S. H. Fritts, G. L. Radde, and W. J. Paul. 1988. Wolf distribution and road density in Minnesota. Wildlife Society Bulletin 16:85-87.

Merriam, G., M. Kozakiewicz, E. Tsuchiya, and K. Hawley. 1989. Barriers as boundaries for metapopulations and demes of Peromyscus leucopus in farm landscapes. Landscape Ecology 2 (4):227-235.

Myers, N. 1993. Biodiversity and the precautionary principle. Ambio 22:74-79.

National Research Council. 2005. Assessing and managing the ecological impacts of paved roads. National Academies Press, Washington, D.C., USA.

Nationa Road Traffic Forecasts (NRTF). 1997. National road traffic forecasts (Great Britain). Department of the Environment, Transport and Regions, London, UK.
OECD. 2002. OECD guidelines towards environmentally sustainable transport. OECD Publications, Paris, France.

Osenberg, C. W., and R. J. Schmitt. 1996. Detecting ecological impacts caused by human activities. Pages 3-16 in C. W. Osenberg and R. J. Schmitt, editors. Detecting ecological impacts; concepts and applications in coastal habitats. Academic Press, San Diego, California, USA.

Ozaki, K., M. Isono, T. Kawahara, S. Iida, T. Kudo, and K. Fukuyama. 2006. A mechanistic approach to evaluation of umbrella species as conservation surrogates. Conservation Biology 20 (5):1507-1515.

Parendes, L. A., and J. A. Jones. 2000. Role of light availability and dispersal in exotic plant invasion along roads and streams in the $\mathrm{H}$. J. Andrews Experimental Forest, Oregon. Conservation Biology 14:64.

Reeve, A. F., and S. H. Anderson. 1993. Ineffectiveness of Swareflex reflectors at reducing deer-vehicle collisions. Wildlife Society Bulletin 21:127-132.

Reijnen, R., and R. Foppen. 1994. The effects of car traffic on breeding bird populations in woodland. 1. Evidence of reduced habitat quality for Willow Warblers (Phylloscopus trochilus) breeding close to a highway. Journal of Applied Ecology 31:85-94.

Reijnen, R., R. Foppen, C. Ter Braak, C., and J. Thissen. 1995. The effects of car traffic on breeding bird populations in woodland. III. Reduction of density in relation to the proximity of main roads. Journal of Applied Ecology 32:187-202.

Sahai, H., and S. Sahai. 1996. Statistics in epidemiology: methods, techniques and applications. CRC Press, Boca Raton, Florida, USA.

Schafer, J. A., and S. T. Penland. 1985. Effectiveness of Swareflex reflectors in reducing deer-vehicle accidents. Journal of Wildlife Management 49(3):774-776.

Sherwood, B., D. Cutler, and J. A. Burton. 2002. Wildlife and roads - the ecological impact. Imperial College Press, London, UK. 
Spellerberg, I. F. 2002. Ecological effects of roads. Land Reconstruction and Management Series, Volume 2. Science Publishers, Enfield, UK.

Stewart-Oaten, A., W. M. Murdoch, and K. R. Parker. 1986. Environmental impact assessment: "pseudoreplication" in time? Ecology 67:929-940.

Sunstein, C. R. 2003. Beyond the precautionary principle. University of Chicago Public Law Working Paper No. 38. University of Chicago, Chicago, Illinois, USA.

Suter, G. W. 1990. Endpoints for regional ecological assessments. Environmental Management 14:9-23.

Suter, G. W. 1993. Ecological risk assessment. Lewis Publishers, Boca Raton, Florida, USA.

Treweek, J. R., S. Thompson, N. Veitch, and C. Japp. 1993. Ecological assessment of proposed road developments: a review of environmental statements. Journal of Environmental Planning and Management 36:295-307.

Trombulak, S. C., and C.A. Frissell. 2000. Review of ecological effects of roads on terrestrial and aquatic communities. Conservation Biology 14 (1):18-30.

Umweltbundesalt (UBA). 2003. Reduzierung der Flächeninanspruchnahme durch Siedlung und Verkehr. Materialienband. Umweltbundesamt Texte 90/03, Berlin, Germany. Available online at: http:// www.umweltdaten.de/publikationen/fpdf-1/2587.pdf

Underhill, J. E., and P. G. Angold. 2000. Effects of roads on wildlife in an intensively modified landscape. Environmental Reviews 8:21-39.

Underwood, A. J. 1992. Beyond BACI: the detection of environmental impacts on populations in the real, but variable, world. Journal of Experimental Marine Biology and Ecology 161:145-178.

Underwood, A. J. 1997. Environmental decisionmaking and the precautionary principle: What does this principle mean in environmental sampling practice? Landscape and Urban Planning 37:137-146.

Underwood, A. J., and M. G. Chapman. 2003. Power, precaution, Type II error and sampling design in assessment of environmental impacts. Journal of Experimental Marine Biology and Ecology 296:49-70.

Van Der Zande, A. N., W. J. Ter Keurs, and W. J. Weijden. 1980. The impact of roads on the densities of four bird species in an open field habitat -evidence of a long-distance effect. Biological Conservation 18:299-321.

Van der Grift, E. A. 2005. Defragmentation in the Netherlands: a success story? GAIA 15(2):144-147.

Vos, C. C., and J. P. Chardon. 1998. Effects of habitat fragmentation and road density on the distribution pattern of the moor frog Rana arvalis. Journal of Applied Ecology 35:44-56. 